\title{
17 INFORMATION TECHNOLOGY AND THE CULTURAL REPRODUCTION OF SOCIAL ORDER: A RESEARCH PARADIGM
}

\author{
Lynette Kvasny \\ Georgia State University \\ U.S.A. \\ Duane Truex III \\ Georgia State University \\ U.S.A.
}

\begin{abstract}
This paper introduces the critical social theory of French sociologist Pierre Bourdieu. The objective of Bourdieu's theoretical framework is to uncover the buried organizational structures and mechanisms that are used to ensure the reproduction of social order. This theoretical framework will be used in a research program that examines the structural processes by which information technology may be constrained from emancipating humankind, and may actually be disempowering and abandoning significant numbers of societal members.
\end{abstract}

Keywords: Bourdieu, critical social theory, cultural capital, field, habitus, organizational change, social reproduction 


\section{Introduction}

Technology may be used for good and for ill. In general, organizational studies on information technology implementation and use assume the neutrality of technology and that the intention of those in power to bring the technology to a given social setting have honorable and nonmalicious intentions. But typically someone, be it management or some class of users, is empowered while others lose power as new technology is deployed. There is a growing body of evidence (McMaster 1999; McMaster, Vidgen, and Wastell 1997; Truex and Ngwenyama 1998) that technology adoption has elements of a zero-sum game.

Information technology may be disempowering significant numbers of societal members. This paper examines how power relations and controls are implicit in the technology and in society's attitudes toward that technology. Hence the deployment of new technology tends to reify the dominant relations in the existing social order. In this paper, we examine the fact that the deployment of information technology is viewed as a mark of cultural distinction, a cultural good. Only people with sufficient levels of cultural awareness tend to consume certain technologies. That is, power relations drive consumption patterns. Thus, one tends not to consume those technologies for which one does not perceive a need or benefit. For instance, people may not conceive of the need for an e-mail account if no one with whom they might communicate has or uses this technology. In this situation, people whose social positions privilege them to believe they should have access to information technology can be expected to gain because they will be motivated to expend symbolic and material resources to acquire these technologies. People whose position in society leads to them to other conclusions can be expected to lose out.

Moreover, those who are culturally privileged sustain their advantage through control of the prevailing attitudes toward cultural goods such as information technology. By defining the cultural value of a technology and its meaning within a social group, those in control of the discourse about technology are in a position to reproduce, sustain, and solidify existing economic and social hierarchies. They may do this in undetectable ways because those controlled may not have sufficient ability to understand the ramifications of information technology. Hence the elite tend to go unchallenged as they maintain the existing social order.

In organizational politics, a fundamental question is: Who wins and who loses from technology change? To date, opinions are mixed. There are those who argue technology enables restructuring of power relationships and those who argue that technology simply reinforces existing power relationships. For example, Bell (1976) and Feidson (1986) have predicted that computer and communication technologies will shift power to technocrats. Romm and Pliskin (1997) have suggested that the use of these technologies will strengthen democratic features of the organizations by providing different interest groups with the tools to respond to their opposition. Ross (1997) argues that software has the power to make knowledge work routine and replace professions in insurance, law, travel, finance, and medicine. Still other researchers suggest that organizational elites typically use their control over resources to shape the acquisition and application of technologies in ways that perpetuate their power (Kirsch 1997; Klein and Kraft 1994; Kraft and Truex 1994; Orlikowski 1991). These appear to be contradictory findings 
when one assumes that structural change implies social change. Bourdieu suggests an alternative way to explain these apparent contradictions.

Bourdieu's theoretical framework helps us understand how changes arising from information technology may actually reinforce existing power structures and help perpetuate the social order. For Bourdieu, change is a self-regenerative mechanism required for the maintenance of stratified organizational hierarchies. Static structures can be figured out and conquered over time. However, changing structures keeps actors off balance, thus leading them to apply familiar strategies in unfamiliar contexts. It is this reuse of learned dispositions in new settings that make existing class positions selfsustaining. According to Swartz (1997), the game is rigged, yet everyone inside the organization must play it out. Those who are culturally (or technologically) disenfranchised have little choice but to participate in the competitive struggle over technological resources despite the fact that there is little chance they will reap any of the benefits.

Until we better understand the reproductive processes enabled and extended through the use of information technology, we may not break the cycle; we will not be able use information technology as a force for universal empowerment. This paper speaks to one effort that is currently trying to understand these processes. It presents a research program designed to explore the nature and degree of the exclusionary aspects of information technology. It is based on a composite critical social theory and poststructuralist framework. It arises from an ideal that technology should be emancipatory rather than enslaving. It is heavily influenced by Bourdieu's theories and empirical studies.

This paper proceeds as follows. The second section explains how computing technologies have been raised to the status of cultural icons. The related myths have selfreproducing and evaluative attributes that characterize technology as a type of capital or power resource. This capital may be husbanded, or misdirected, thus enforcing social roles and stereotypes. This section is designed to convince the reader that these selfreproducing hierarchies should become a focal point of further study. The third section introduces Bourdieu's theory of practice and cultural reproduction. The final sections describe how this theoretical framework may guide an information systems research program.

\section{Motivation: Technology as Cultural Icon and Myth}

Kling (1998) argues that a popular cultural representation of computing should be taken as a serious influence on the ways that people will use systems as well as on their likely social impacts. Accepting this view necessarily means that the adoption of computers involves much more than installing and using software, hardware, and networks. Organizations are also adopting the cultural value assigned to the technology by "the new tastemakers"- -vendors, consultants, and the media. These cultural values shape the manner in which people learn about potential social roles that will be attached to new forms of computing.

Over time, the original limiting context that accompanied the adoption of computers and defined their use may be extended into ways that further reify social inequality within the organization. For instance, Marshall McLuhan (Postman 1985) states that the clearest way to see through a culture is to look at its tools for conversation. Every media favors 
a particular kind of content and wields influence on the wider culture. Information technology makes possible a new mode of dominant discourse by providing a new orientation for thought and expression. Arguably, the most dramatic change fueled by technology adoption is that it helps define and regulate society's conception of ideas of truth. There is a certain degree of bias in the form that any attempt at truth telling can take. The weight assigned to any particular form of truth telling is influenced by the choice of the communication medium (Postman 1985). Therefore, what the culture claims as significant is subject to change with the introduction of a new communication medium and its attributed values. The cultural importance of technology also grows as the organization's dependency on technology increases. As a result, technology can achieve mythical status wherein its historicity and human construction are no longer evident to people (Turkle 1995).

Myths are ways of understanding the world that are so deeply embedded in an actor's conscious that they become invisible (Barthes 1957). When a concept or icon achieves the status of myth, it becomes part of the "taken-for-granted" assumptions about the order of things. The culture adjusts and embraces those myths. Embracing those myths allows for apparently irrational behaviors such as the continued investment in technology firms that have yet to make a profit; the continued proliferation of computers into schools even though educators do not yet know how to effectively integrate technology into the curriculum (PCAST 1997); and the continued reference to the "information society" even when large segments of the population are systematically excluded from participation (Goslee and Conte 1998; NTIA 1995).

As information technology takes on increasing importance within the culture, the computer is afforded the status of icon with "the computer" being rather like a force of nature that shapes our knowledge about the world as well as our ways of knowing the world. Hence, it is important to broaden our understanding of the computer as a cultural medium, not merely a technology. Moreover, we need to view the socio-political aspects of computing as societal in scope and not simply limited to individual organizations. As a cultural artifact, the computer contains different content, uses, meanings, and power. It becomes a credible form of truth telling, and consequently virtual environments may become replacements for certain aspects of reality. This reliance on the computer is part of something much larger: the spread of a civilization so dominated by technology that those who master these tools are positioned to wield an enormous influence over our social, technical, cultural, and economic policies (Swerdlow 1997).

What theoretical framework can one apply to questions involving practice, power, culture, structures, and issues of agency? Critical social theory explicitly deals with these issues (c.f., Ngwenyama 1991). Yet even in the realm of critical social theories, there are those particularly amenable to this mix of issues. The following section introduces the critical social theory of Pierre Bourdieu as a framework capable of helping us better understand how information technology may at one and the same time be both enabling and disempowering.

\section{Bourdieu's Theory of Practice and Cultural Reproduction}

The work of French sociologist Pierre Bourdieu is a type of neostructuralist critical sociology of a class Morrow (1994, p. 132) calls genetic or critical structuralism. 
Bourdieu focuses on the visible social world and develops a model of social practice. He terms his approach socioanalysis, where the role of the researcher is to unveil the "social unconscious" of the social group under investigation (Bourdieu 1984). The social unconscious consists of those unacknowledged interests that actors follow as they participate in a hierarchical social order. According to Bourdieu, the failure to recognize these embedded interests is a necessary condition for the exercise of power by one group upon another. For Bourdieu, the public exposure of embedded interests can help undermine their apparent legitimacy and open up the possibility for altering existing social arrangements. In this respect, Bourdieu's sociology is complementary to other forms of critical social theory (Morrow 1994). However, Bourdieu differs from the Frankfurt school of critical social theory (notably the work of Jürgen Habermas) and from English critical social theory (notably the work of Anthony Giddens).

Where Habermas assumes an ideal state wherein parties share a common goal that is the basis for communicative action, Bourdieu sees symbolic structures (including language) and material structures as formed to serve strategic purposes; typically, to empower or disempower. Thus, in this sense, Bourdieu's theory is one of conflict whereas Habermas' theory, ideally, is one of compromise.

For Bourdieu, as with Habermas, a central issue of concern is practice: that is, the outcome of the dialectical relationship between how social actors construct social reality and how structure constrains or enables them. The exercise and reproduction of classbased power informs all practice. In Bourdieu's case, the strong focus on the constraining and enabling features of structure on human action has earned his work the label of "genetic structuralism." Whereas structures for Habermas are largely the result of technical language, Bourdieu posits that structures not only exist in language, but in the social world as well. These "mental structures" take place in an arena that is both animated and constrained by "social structures" (Ritzer 1996).

In the realm of the agency-structure debate, Bourdieu is closer to Giddens as both attempt to bridge the divide between agency and structure. But unlike Giddens, Bourdieu gives more credence to the limiting or conversely enabling aspects of social structures. These structures may be vicious and negative, entrapping structure for the cultural "have nots," or they may positively enable and reinforce privilege for the cultural "haves."

In Giddens' conceptualization of social systems, they do not have structures; rather, they exhibit structural properties. In this view, structure is manifested in social systems in the form of reproduced practices. These social systems are often the unanticipated consequences of human action. On occasion, they are the product of intentional action. Social systems are also manifest in the memory of agents and, as a result, these rules manifest themselves at both a macro and micro level of human consciousness. Thus, for Giddens, the central issue of social order depends on how well social systems are integrated over time and space (Ritzer 1996). Bourdieu posits that structures change over time and space as actors pursue cultural distinctions. However, while structures evolve, positions in the hierarchy remain largely unchanged. Practices serve to reify social structure (Berger and Luckman 1966; Swartz 1997).

Bourdieu takes a critical view of the intentionality of human actions and their consequences, whereas Giddens is more concerned with the consequences than the intentions of social actors. (For example, I have hit you with my car and you have died. The fact that I didn't intend to hit you with my automobile doesn't change the 
consequences of the act.) Although both theorists see social systems as being integrated over time and space, for Bourdieu, the intent of social practices is to hold actors in selfgenerating and self-perpetuating social hierarchies. Therefore, practice is tacit and motivated largely by the actor's position within the class structure.

\subsection{Bourdieu's Epistemology}

In The Logic of Practice (1990), Bourdieu provides a critique of theoretical reason. Like Habermas and Giddens, Bourdieu's social theory attempts to overcome the apparent duality between subjectivism and objectivism. Bourdieu argues that these epistemologies, when employed in isolation, provide an impoverished view of social life. To gain a richer understanding of social phenomenon, Bourdieu suggests a two-step reflexivity process, which forces one to consider both sides of the coin. ${ }^{1}$

Subjectivism focuses on the lived experience of the actor, which takes the social world as self-evident. However, subjectivism is limited because it excludes questions about the internalization of social structures that make lived experiences possible. These subjective perceptions can only reinforce the system of domination that is under investigation. Since all human action is situated within determining structures that are not readily apparent in everyday consciousness, the researcher must focus on theoretical practices. This requires critical reflection on the research practice itself, and is essential for establishing the "validity" of the accounts of social phenomena. ${ }^{2}$ This is especially important for critical researchers concerned with charges that their work is biased by their own ideologies (Schwandt 1997).

Conversely, objectivism sets out to grasp objective regularities, such as structures, laws, and systems of relationship, that take place irrespective of individual consciousness and will. It assumes the existence of social structures well outside the realm of the individual that exert force over actors. However, objectivism ignores the experiences that are both the condition and the result of structuring operations. Therefore, this epistemology cannot account for the generative features of practice. Bourdieu argues that the researcher must focus on the generative as well as situated character of practice and provides several key concepts to enable the investigation of these dual characteristics of practice.

\subsection{Bourdieu's Key Concepts of Practice and of Social Control}

Bourdieu makes reference to a number of concepts requiring introduction and explanation. He uses the concepts of the field and of the habitus to model practice.

\footnotetext{
${ }^{1}$ In this sense, he shares an approach suggested by Latour (1988). We intent to examine the intersection of Bourdieu and Latour in further work, but this analysis lies outside the scope of this paper.

${ }^{2} \mathrm{We}$ are quite aware of the host of objections this may raise in the IFIP WG 8.2 research community. Suffice it to say that ours is a hybrid notion that is far from the positivist notions of validity. It is also very different from the "any old interpretation counts" approach. See Baskerville and Lee (1999) for an excellent discussion of this point.
} 
Fields are Bourdieu's notion of social arenas within which individuals struggle to maximize social standing. Fields may be defined as competitive systems of social relations functioning according to rules specified by dominant classes. Hence, in the composite, fields are a social arena within which struggles take place over the accumulation, investment, and conversion of power resources. The outcomes of these struggles influence cultural distinctions. Thus, a field defines the structure of the social setting in which the habitus operates (Swartz 1997). One may, therefore, view society itself is a system of social fields (Morrow, 1994).

The habitus guides practice and behavior in daily life. It is a cognitive construct that arises or "is generative" from personal experience and history. Elements of the habitus are acquired from the social class and status into which one is born. It is, therefore, both an individual and a shared concept. That is, one has one's own habitus reflecting one's place in a social structure. But the habitus is not fixed. Rather, while it is durable it is yet malleable, and is in constant negotiation with the world. So it may be seen as a kind of shield in the field of social battle. For instance, if one's habitus has been one of relative social privilege, it serves as a template and provides strategies for continued success. But if one's habitus has been one of relative powerlessness, it provides coping strategies. On the negative side, the habitus may limit social progress in that it defines expectations of the possible and, worse yet, may limit one's aspirations.

Bourdieu employs three additional concepts to model a political economy of symbolic power: cultural arbitrary, capital, and symbolic violence. According to Bourdieu, behind all culture is power in the form of the cultural arbitrary: standards put forth and managed by privileged or ruling classes. These standards explicitly and implicitly determine which capital or stakes are of value and are to be acquired in continuing struggles within fields. Thus capital extends the concept of power to include material and symbolic resources.

Cultural capital is a particularly important in that without it one cannot make cultural distinctions and value judgements. Without the proper cultural capital, one can neither consume nor produce cultural goods. This holds for music, art, scientific formulas, information systems research methods, and computing technology. For instance, if presented with a famous painting by Monet, one might see it as a pretty representation of lily pads on a pond. But with additional cultural capital, one would be better able to understand the significant. One may also understand how it fits into the history of art and particular historical events and, therefore, is deemed to have cultural value.

Symbolic violence is power employed within the field to legitimate and reproduce the class hierarchy. This is pure power exercised through hegemony of norms and political techniques for shaping the mind and the body without the use of physical force or laws (Best and Kellner 1991). Through ideology and discourse, people are trained via the cultural arbitrary as to their place in society and what they may expect from society. In this process, symbolic violence inculcates the habitus to produce durable, but changeable, dispositions. Thus the interplay of symbolic violence and the counter strategies employed by the actor provides the habitus with an ongoing history of continually adjusting and self-perpetuating experiences. This generative habitus coupled with the constraints, demands, and opportunities present in the field determines practice. Through practice, actors struggle and pursue strategies to achieve self-interests within a field. However, in doing so, actors reproduce the class and social structure without 
conscious recognition and without resistance (Swartz 1997). Capital, and symbolic violence are related as follows: if one doesn't have the right kind or the sufficient amount of capital it is more likely that he or she will be the victim of symbolic violence.

\section{Bourdieu in the Domain of Information Technology}

Table 1 gives a high level summary of the most salient elements of Bourdieu's theory applied to the domain of information technology. The table and accompanying text in this section are intended to illustrate how Bourdieu's ideas better inform our understanding of technology empowerment and disempowerment. More importantly, this theory suggests how the application of technologies, even when conceived egalitarian motives and a desire to see the technology made available universally, may exclude entire classes of people.

\section{Table 1. Key Theoretical Concepts}

\begin{tabular}{|l|l|}
\hline Key Term & Application to Information Technology \\
\hline Field & $\begin{array}{l}\text { Information technology organization or a given technology } \\
\text { system under investigation }\end{array}$ \\
\hline Habitus & $\begin{array}{l}\text { Expectations, aspirations, and attitude towards technology; } \\
\text { informs practices, e.g., how and if one engages technology }\end{array}$ \\
\hline $\begin{array}{l}\text { Symbolic } \\
\text { Violence }\end{array}$ & $\begin{array}{l}\text { Use of technology to enforce decisions; decision to limit or } \\
\text { deny access to technology or use of technology; technology } \\
\text { used for surveillance or control }\end{array}$ \\
\hline Cultural Capital & $\begin{array}{l}\text { Exposure, previous experience and familiarity with } \\
\text { information technologies; information technology credentials }\end{array}$ \\
\hline Symbolic Capital & $\begin{array}{l}\text { Use of highly technical language, sharing of technical } \\
\text { expertise, removing manual process in favor of technological } \\
\text { processes, denying training in new technology }\end{array}$ \\
\hline Social Capital & $\begin{array}{l}\text { Access to relationships with others knowledgeable about } \\
\text { technology }\end{array}$ \\
\hline Economic Capital & $\begin{array}{l}\text { Ability to acquire technology and training; choices to allocate } \\
\text { resources to the procurement of technology }\end{array}$ \\
\hline
\end{tabular}

\subsection{Field}

A field is the social arena under investigation. This could be an entire industry, an organization dedicated to the development of information systems, or even a virtual community. The researcher may also choose to narrow the focus and investigate a particular information system or business process employed within an organization.

Autonomy is a particularly important measure of the reproductive tendencies of a field. Autonomous fields are those that are more or less free from political intervention and economic constraints from external institutions and, therefore, have greater control 
over the creation and management of their culture. Autonomy may be enacted through formal methods, procedures, and practices such as hiring, promotion, business planning, and procurement of information technology resources.

In terms of the information systems development organization, autonomy may signal a move to an organization of specialists who are able to progressively develop, transmit, and control their own particular culture. Thus, this group is able to promote its own organizational and professional interests, which may deviate significantly from external interests. With growing autonomy comes the capacity to retranslate and reinterpret external demands to serve the interests of the dominant organization members. Stated more theoretically, a highly autonomous field has greater ability to control the reproduction of the existing social order because it can independently establish criteria for legitimizing the cultural arbitrary (Swartz 1997). Stated more plainly, those with power can use technology to concentrate power. Capital breeds capital.

\subsection{Habitus}

The habitus is a product of the internalization of the cultural arbitrary. In the information system development organization, for example, the cultural arbitrary confers privileged status to those with expert technical knowledge. The habitus of the software developers has internalized this cultural valuation, which drives their practice to accumulate and convert expert knowledge. Expert knowledge, therefore, becomes an object of cultural distinction used to differentiate and classify actors within the organizational hierarchy.

For instance, Reed (1996) found that software developers not only build information systems to further increase monitoring capabilities of management; developers also monopolize scarce knowledge so that it can't be stolen or duplicated. Reed also describes the politics of expertise where trends such as telecommuting are fragmenting technologists, thereby decreasing their collective power base. However, those who are able to "black box" their expertise - compartmentalize, simplify, and standardize their knowledge in a more portable form - are able to retain their privileged status within the organization. The growing use of credentials by information systems professionals provides an example of how actors attempt to black box expert knowledge (Knights 1992). This demonstrates how the software developers' habitus provides selfpreservation strategies that enable them to institute practices that maintain their social position as the structure of the field changes.

\subsection{Symbolic Violence}

Bourdieu describes the three functions of symbolic violence as (1) knowledge integration, (2) communication, and (3) political domination. The information systems literature on power and politics provides examples of these functions. Typically these studies employ a framework that divides organizational control mechanisms into two categories: formal controls and informal controls (Eisenhardt 1985; Henderson and Lee 1992; Kirsch 1996, 1997; Ouchi 1979, 1980). Formal controls drive behaviors and outcomes through bureaucratic measures; they relate to the knowledge integration function of symbolic 
violence where written policies, procedures, and methodologies are employed to provide a universal ordering and understanding of the social arena.

Informal controls are derived from clan norms or self-regulation within social classes. Informal controls correspond to the communication function of symbolic violence where controls are embodied in codes that channel deep structural meanings shared by all members of a social class. These deep structural meanings are the result of the collective habitus of actors within a social group.

The final function of symbolic violence, and the function that Bourdieu stresses, is political. The political function of symbolic violence is the process whereby order and social restraint are provided by indirect, cultural mechanisms rather than by direct, coercive social control. This form of symbolic violence is often inflicted with the imposition of technology and the associated dominant-class culture on subgroups (Swartz 1997). For example, Kling and Iacono (1984) found that managers gain their authority and resources through a project champion or steering committee. Together they form a cohort that builds ideology and legitimacy in order to increase the acceptance of information systems. The champion performs "symbolic labor," that is, the masking of the interested practices of managers. Symbolic violence is most powerful when it hides the interested nature of managerial actions and the acceptance of the information systems by the users serves to further perpetuate their domination.

The political function of symbolic violence is also inflicted through the use of surveillance which enables an outsider to observe and penetrate behavior. At the same time, the actor internalizes the gaze and regulates her behavior because she is never certain when she is under the gaze (Foucalt 1979). Monitoring telephone calls, examining computer usage logs, and maintaining statistics on the entire workforce place all workers under the gaze. Information systems extend and enhance the exercise of power by an organization, thereby enabling the actions of workers to be supervised by entire managerial groups, not just the immediate supervisor. Supervision with information technology can also overcome time and space distances. Whether the worker sits directly across from the manager or telecommutes from her home, the manager is able to monitor the work effort.

In addition to the use of technology, symbolic violence is enacted via organizational processes such as performance feedback and training programs. Performance evaluations are used to rank and rate workers. These ratings serve to individualize workers by making the individual more identifiable vis-à-vis other individuals, while rankings serve to individuate workers by converting individuals into numerical equivalents. Performance evaluations also serve as a confessional where employees are given performance feedback that becomes part of the individual's self-knowledge. The organization strives to control what employees know through the use of formal and informal training programs and examinations. Through these acts of symbolic violence, the organization trains the habitus and, therefore, controls the practices, cultural preferences, aspirations and expectations of actors.

In all cases, the symbolic violence must be "misrecognized" if it is to be successfully imposed on a subculture. That is, the symbolic violence must be seen as a legitimate call for deference to authority, otherwise actors may resist the imposition. For instance, a study by Orlikowski concluded that management introduced CASE technology to formalize and tighten their control over the work practices of consultants. However, the 
consultants found passive ways to undermine the oppressive software and were, therefore, able to resist the imposition of the technology. An abundance of cultural capital and a habitus generated from a history of privilege enabled the consultants to recognize that symbolic violence was being inflicted upon them and led the consultants to adopt selfpreservation practices to maintain their interests.

\subsection{Cultural Capital}

Ownership of and familiarity with information technology is a type of cultural capital in the same manner as in the art example in section three. It is simply expected that one is confident with technology in business settings. It is a mark of the well educated and erudite. Unless one is socialized in a culture of information technology acceptance and history, one is rather like the indigenous aboriginal people with minimal exposure to the outside world in the film The Gods Must Be Crazy. When technology, in the form of a discarded Coke bottle, is encountered, their frames of reference cannot incorporate it into their lives.

Similarly, formal language is a type of cultural capital. More so than any other technology, computing has developed its own extensive and unique lexicon. While the ability to speak intelligently about technology in a business setting immediately signals one's position as upper class, it forces those without a command of the language of technology to a position of deference. Bell (1976) argues that formal language is the central resource in society. However, formal language by definition is not part of everyday vocabulary but the importance of possessing this type of knowledge has grown enormously in advanced post-industrial societies. Thus knowing about technology is an elite form of knowledge, and prestige and respect are given to the technocrats that possess this form of cultural capital (Feidson 1986).

The HomeNet field trials (Kraut et al. 1997) provide empirical support for this notion of cultural capital. This study found that even when technology and helpdesk support was provided, participants were still reluctant to utilize these resources for technical assistance. Winter, Gutek, and Chudoba (1997) noted similar results in their study of the computer literacy of user groups. Respondents to that survey indicated that they rely on peers rather than access a helpdesk in solving their computer problems. In both studies, the participants did not have sufficient cultural capital to self manage the information technology, which forced them to rely on the expertise of others. Rather than defer problem resolution to external groups with greater expertise, the participants preferred to either abandon the technology altogether or find the expertise they needed within their social group. This indicates that, without sufficient cultural capital, the habitus of these actors led them to focus internally to develop coping strategies.

\subsection{Symbolic Capital}

Symbolic capital is gained when the exercise of power goes unnoticed. It is the use of power in disguised form because it hides underlying interests in order to give them legitimacy. The potency of symbolic capital lies in the fact that it is not perceived as 
power but as legitimate demands for recognition, deference, obedience, or the service of others (Swartz 1997). By simply conforming to the control mechanisms instituted by managers, workers unwittingly provide management with knowledge that may be used to further manipulate the workforce.

For example, Townley (1993) examined how managerial practices such as performance evaluations, time reporting, and the computerized information systems for monitoring job performance are used to order the population. In all cases, emphasis is on the development of regulatory systems and written policies that record, calculate, observe, and audit employees. Once captured in a database, this information becomes a domain of truth that can be easily translated to other decision-making bodies. Townley concludes that the knowledge obtained through these control systems engenders power because. management exercised their privileged status to accumulate the information.

Knights (1992) makes a similar observation when he states that management knowledge is never independent of the power that managers and corporations exercise. Whereas Townley is concerned with the proliferation of information into areas beyond its intended uses, Knights argues that computer records can be used to individuate the worker, constituting the individual as a describable, analyzable object. Technology becomes a tool for normalizing procedures of exclusion where surveillance can be used to physically separate deviants and the incompetent. Knowledge is, therefore, a form of symbolic capital that is firmly rooted in power and authority. Deviance is not merely discovered; knowledge creates entities such as the deviant and the incompetent (Foucalt 1979).

\subsection{Social Capital}

Information technology also embodies social capital as it opens doors to new relationships, both physical and virtual. With a desktop computer, employees can "network on the network" to search for employment opportunities, seek career advice, and retrieve industry reports that will help them to improve their job performance. White-collar workers can also use the intranet as a political lobbying tool to benefit not only their professional career, but also to support their personal interest (Romm and Pliskin 1997). With access to e-mail, listserves, newsgroups, and web sites, white-collar workers can also use technology to form business related or purely recreational virtual friendships.

\subsection{Economic Capital}

Economic capital enables one to convert economic resources into information technology resources. Because of its universal applicability and liquidity, economic capital can be defined as the root of all other capitals. In fact, all other forms of capital can be thought of as disguised forms of economic capital (Swartz 1997). For instance, with sufficient economic capital, one can leave the workforce to acquire additional cultural capital through advanced degree programs. In a society where hierarchies are often based on education, additional education buys legitimacy and access to social circles in which one 
may develop relationships with influential people within different communities of practice.

\section{Relevance of Theory}

Bourdieu's theoretical framework helps us understand how change arising from information technology may serve to both disrupt social order and still perpetuate existing power structures. While the introduction of technology may provide opportunities for groups and individuals to gain autonomy, the dominant can ensure their privileged position by enacting mechanisms to monopolize their control over scarce and valuable organizational resources. Information technology extends the power resources from which actors may draw upon in their struggle to maximize social position. For instance, new domains of knowledge and mechanisms for control become available with the emergence of technologies such as data mining, knowledge management, and data warehousing. These practices are motivated, consciously or unconsciously, by pursuits for material and symbolic profits.

The contribution of this framework to information systems research lies in the ability to explain and measure the reproductive tendencies of technology in diverse settings such as community, organizational, society, or international studies. This suggests that social order may be an unseen contingency in numerous information systems research areas. For example, changes in job classifications and the rise of new occupations may be explained by the "broken trajectory" effect. This occurs when an agent's aspirations soar above their objective chances. Broken trajectories often occur for those who have not obtained the rewards which their qualifications would have guaranteed in an earlier state of the market. The disparity between aspirations that the educational system produces and the structural reality of the marketplace takes forms that are objectively and subjectively different in the various social classes (Bourdieu and Passeron 1979). The researcher would seek to uncover strategies employed by actors of various social backgrounds to avoid structural downclassing. For instance, one may see the production of new occupations more closely matching the actor's pretensions, or the refurbishment of occupations to which the actor's qualifications do give access. Historical studies of the rise of software consulting firms and computer-related occupations and survey research that examines trends in job placements for college graduates may be informed by this type of social stratification analysis.

Social class analysis may also be relevant in information systems development studies. Because of their highly specialized skills, developers and analysts are granted authority to interpret and translate business requirements into computer systems. However, these functional requirements are sometimes reinterpreted during system design and the resulting information system doesn't perform as expected. This theory would suggest that information systems development is a form of symbolic violence with developers and analysts assuming the role of cultural producers capable of imposing their worldview on the unsuspecting users of their technology products and service.

This theory would also suggest that users and developers are predisposed to develop new information systems that reflect the socialization learned by their habitus. Therefore, calls for participatory design and end user involvement may be questioned because all 
parties will tend to build systems that reflect their social position. This hypothesis could be tested with a laboratory experiment where participants would be socialized under an initial social order. The participants would then be given specifications that would force them to design an information system that required a different social arrangement. The researcher would be able to measure the reproductive tendencies of an information development effort and determine if one is even able to develop a system outside of one's habitus.

\section{Research Approach}

Bourdieu's theory of practice and cultural reproduction is useful for examining the relationship between structure, culture, and social class. Bourdieu is a cultural anthropologist, a social theorist, and a prolific empirical researcher. Based on the findings of his empirical studies, Bourdieu's theory is under constant refinement and extension. Bourdieu uses intensive field-based research methodologies and focuses on statistical patterns of relationships gleaned largely from participant observation, document analysis, interviews, and multivariate statistical techniques.

What tools of discovery and analysis may be best brought to bear when using Bourdieu as a theoretical guiding force to examine the role of information technology in organizational settings? What are the units of analysis? How may one frame proper hypotheses and research questions? The answer to each of these questions is, of course, driven by the research question itself. We envision a three phase research agenda for ourselves. It is one that (1) explores specific organizational structures and procedures that serve to either maintain or change the various capital structures described by Bourdieu; (2) identifies cultural features within study organizations that maintain, or on occasion enable, adjustments to the social order (this will allow a further examination of interorganizational cultural and technological hierarchies); and (3) identifies and studies groups and individuals that have "broken the mold," escaped the structural limitations and have moved to new positions in the hierarchy. This agenda will require learning about the struggles and types of symbolic violence employed in organizations. It also requires uncovering and understanding underlying assumptions, beliefs and values about technology within social/cultural strata in organizations.

This research agenda requires a mixed methods approach. We expect that intensive ethnographic fieldwork will be required during the data collection phase. The data will be participant observation field notes and transcripts of conversations with organizational actors as well as organizational documents. The data will be subjected to interpretative discourse analysis. Structured interviews will be mapped using cognitive mapping techniques. All texts will be iteratively examined and will subsequently provide the basis for a deconstructive reading of the organizational setting. Identifying specific organizational practices coupled with Bourdieu's previous work will enable us to develop appropriate instruments for further work. We would like to contribute to the development of a kind of index to measure and "predict" Bourdieu's notion of life's chances.

Why? Frankly, we want to change the world. We believe that the promise and benefits of information technology should be more equitably distributed. A first step requires knowing more about how various types of organizational life contribute to 
limiting or supporting access to the promises of these technologies. Armed with that knowledge, ethical designers and managers of information technology may be able to counter forces that are arrayed to enslave rather than empower.

\section{Summary}

This paper introduces the social theory of Pierre Bourdieu and describes an information systems research program guided by this theoretical framework. This research program assumes a view of technology as a cultural good that serves as a marker of class distinction. Actors with sufficient cultural capital have acquired an appreciation for technology that enables them to readily consume this cultural good. However, actors with inadequate levels of cultural capital are unable to partake in the potential benefits of technology because they are systematically excluded from the discourse surrounding technology. This research agenda seeks to examine how and why technology is used to reproduce a social order that perpetuates the privileged status of some actors while simultaneously disenfranchising others. Until we understand the processes better, we may not break out of the cycle of social reproduction; we will never be able to use information technology as a more universal force for human empowerment.

\section{References}

Barthes, R. Mythologies. New York: Hill and Wang, 1957.

Baskerville, R., and Lee, A. "Distinctions Among Different Types of Generalizing in Information Systems Research," in New Information Technologies in Organizational Processes: Field Studies and Theoretical Reflections on the Future of Work, O. Ngwenyama, L. Introna, M. Myers, and J. I. DeGross (eds.). Boston: Kluwer Academic Publishers, 1999, pp. 49-65.

Bell, D. The Coming of Post-Industrial Society: A Venture in Social Forecasting. New York: Basic Books, 1976.

Berger, P., and Luckman, T. The Social Construction of Reality: A Treatise in the Sociology of Knowledge. New York: Anchor Books, 1966.

Best, S., and Kellner, D. Postmodern Theory: Critical Interrogation. New York: The Guilford Press, 1991.

Bourdieu, P. Distinction: A Social Critique of the Judgement of Taste. Boston: Harvard University Press, 1984.

Bourdieu, P. The Logic of Practice. Stanford, CA: Stanford University Press, 1990.

Bourdieu, P. In Other Words: Essays Toward a Reflexive Sociology. Stanford, CA: Stanford University Press, 1990.

Bourdieu, P., and Passeron, J. The Inheritors. Chicago: University of Chicago Press, 1979.

Eisenhardt, K. "Control: Organizational and Economic Approaches," Management Science, (2:31), 1985, pp. 134-149.

Feidson, E. Professional Powers: A Study of the Institutionalization of Formal Knowledge. Chicago: University of Chicago Press, 1986.

Foucalt, M. Discipline and Punish: The Births of the Prison. New York: Vintage Books, 1979.

Goslee, S., and Conte, C. "Losing Ground Bit By Bit: Low-Income Communities in the Information Age," 1998 (available online from http://www.benton.org/Library/Low-Income; accessed December, 1999). 
Henderson, J., and Lee, S. "Managing I/S Design Teams: A Control Theory Perspective," Management Science (6:38), 1992, pp. 757-777.

Kirsch, L. "The Management of Complex Tasks in Organizations: Controlling the Systems Development Process," Organization Science (7:1), 1996, pp. 1-21.

Kirsch, L. "Portfolios of Control Modes and IS Project Management," Information Systems Research (8:3), 1997, pp. 215-239.

Klein, H., and Kraft, P. "Social Control and Social Contract in NetWORKing: Total Quality Management and the Control of Knowledge Work in the United States," Computer Supported Cooperative Work (CSCW), 1994, pp. 89-108.

Kling, R. "Cultural Influences on the Process and Impacts of Computerization," in Fostering Research on the Economic and Social Impacts of Information Technology, H. Varian (ed.). Washington, DC: National Academy of Science, 1998, pp. 150-151.

Kling, R.,and Iacono, S. "The Control of Information Systems Developments After Implementation," Communications of the ACM (27:12), 1984, pp. 1218-1226.

Knights, D. "Changing Spaces: The Disruptive Impact of a New Epistemological Location for the Study of Management," Academy of Management Review (17:3), 1992, pp. 514-536.

Kraft, P., and Truex, D. "Postmodern Management and Information Technology in the Modern Industrial Corporation," in Information Technology and New Emergent Forms of Organizations, R. Baskerville, S. Smithson, O. Ngwenyama, and J. I. DeGross (eds.). Amsterdam: Elsevier Science Publications, 1994, pp. 113-127.

Kraut, R., Scherlis, W., Mukhopadhyay, T., Manning, J., and Kiesler, S., "The HomeNet Field Trial of Residential Internet Service," Communications of the ACM(38:12), 1997, pp.55-63.

Latour, B. Science in Action: How to Follow Scientists and Engineers Through Society, Boston: Harvard University Press, 1988.

McMaster, T., Vidgen, R., and Wastell, D. "Technology Transfer-Diffusion or Translation?" in Facilitating Technology Transfer Through Partnership: Learning from Practice and Research, T. McMaster, E. Mumford, E. B. Swanson, B. Warboys, and D. Wastell (eds.). London: Chapman \& Hall, 1997, pp. 64-75.

McMaster, T., Vidgen, R., and Wastell, D. "Networks of Association and Due Process in IS Developmentm," in Information Systems: Current Issues and Future Changes, T. J. Larsen, L. Levine, and J. I. DeGross (eds.). Laxenburg, Austria: IFIP, 1999, pp. 341-357.

Morrow, R. Critical Theory and Methodology. Thousand Oaks, CA: Sage Publication, 1994.

Ngwenyama, O. "The Critical Social Theory Approach to Information Systems: Problems and Challenges," in Information Systems Research, H-E. Nissen, H. Klein, and R. Hirschheim (eds.). Amsterdam: Elsevier Science Publications, 1991, pp. 267-294.

NTIA. "Falling Through the Net: Defining the Digital Divide,"National Telecommunications and Information Administration, Department of Commerce, Washington, DC, 1999 (available online from http://www.ntia.doc.gov/ntiahome/ fttn99/contents.html; accessed December, 1999).

Orlikowski, W. "Integrated Information Environment or Matrix of Control? The Contradictory Implications of Information Technology," Accounting, Management, and Information Technology (1:1), 1991, pp. 9-42.

Ouchi, W. "A Conceptual Framework for the Design of Organizational Control Mechanisms," Management Science (9:25), 1979, pp. 833-848.

Ouchi, W. "Markets, Bureaucracies, and Clans," Administrative Science Quarterly (3:25), 1980, pp. 129-141.

Postman, N. Amusing Ourselves to Death. New York: Penguin Books, 1985.

PCAST. "Report to the President on the Use of Technology to Strengthen K-12 Education in the United States," President's Committee of Advisors on Science and Technology, Panel on Educational Technology, 1997 (available online from http://www.whitehouse.gov/WH/EOP/ OSTP/NSTC/PCAST/k-12ed.html; accessed December, 1999). 
Reed, M. "Expert Power and Control in Late Modernity: An Empirical Review and Theoretical Synthesis," Organizational Studies (17:4), 1996, pp. 573-597.

Ritzer, G. Modern Sociological Theory. New York: McGraw-Hill, 1996.

Romm, C., and Pliskin, N. "Toward a Virtual Politicking Model," Communications of the ACM (40:11), 1997, pp. 95-100.

Ross, P. "Software as Career Threat," in Computers and Society, P. Winters (ed.). San Diego: Greenhaven Press, 1997, pp. 44-48.

Schwandt, T. Qualitative Inquiry: A Dictionary of Terms. Thousand Oaks, CA: Sage Publications, 1997.

Swartz, D. Culture and Power: The Sociology of Pierre Bourdieu. Chicago: University of Chicago Press, 1997.

Swerdlow, J. "Computers and Society: An Overview," in Computers and Society, P. Winters (ed.). San Diego: Greenhaven Press, 1997, pp. 16.

Townley, B. "Foucault, Power/knowledge, and Its Relevance for Human Resource Management," Academy of Management Review (18:3), 1993, pp. 518-545.

Truex, D., and Ngwenyama, O. "Unpacking the Ideology of Postindustrial Team-Based Management: Self-governing Teams as Structures of Control of IT Workers,"paper presented at the Work, Difference and Social Change: Two Decades After Bravermans's Labor and Monopoly Capital, Binghamton, New York, 1998.

Turkle, S. Life on the Screen: Identity in the Age of the Internet. New York: Simon \& Schuster, 1995.

Winter, S., Gutek, B., and Chudoba, K. "Misplaced Resources? Factors Associated with Computer Literacy Among End Users," Information \& Management (32:1), 1997, pp. 29-42.

\section{About the Authors}

Lynette Kvasny is a doctoral candidate specializing in Computer Information Systems at Georgia State University. Her teaching experience includes Introduction to Business Information Systems, Database Management Systems, and Object-Oriented Programming in $\mathrm{C}++$. Her research interests focus on various social aspects of computerization including the roles of information technology in societal and organizational change, the uses of information technologies in socio-political contexts, and the ways that technology utilization are influenced by social forces and practices. She also has several years of software development and consulting experience at AT\&T, Bell Laboratories, and Lucent Technologies. Lynette can be reached at lkvasny@gsu.edu.

Duane Truex is an assistant professor of Computer Information Systems at Georgia State University and a Leverhulme Fellow at the University of Salford, England. His first degrees were in the arts and he spent his early professional life in symphony orchestra and museum management. As a critical social theorist, his work in information systems research has been generally concerned with emancipatory issues of information technologies. He also writes about information systems development and IS research methods. He has published in Communications of the ACM, Accounting Management and Information Technologies, Information Systems Journal, IEEE Transactions on Engineering Management, the IFIP transactions series, and in various other proceedings. Duane can be reached at dtruex@gus.edu. 